https://doi.org/10.48009/1_iis_2010_41-47

\title{
A LONGITUDINAL STUDY OF FINANCIAL EXECUTIVES' VIEWS ON INFORMATION SYSTEMS RETURNS AND KEY TECHNOLOGY ISSUES
}

\author{
Alan R. Peslak, Penn State University, arp14@psu.edu
}

\begin{abstract}
Understanding important information technology issues is essential to improving organizational performance and preparing proper curriculum to educate new IT students. However, key information technology issues have been lightly studied in peerreviewed literature. This manuscript studies the views of top financial executives over the three year period 2003 to 2006. A large sample of major executives share their views on the returns currently generated from information systems in their organization. Overall a group of approximately 500 executives participated in the survey. Generally, Information Systems (IS) are seen as providing worse than medium returns both in 2003 and 2006. However, it has been determined that there have been returns on information technology investment are seen to have increased. By and large there were many issues that showed significant decline as "very critical" technology issues between 2003 and 2006. The specific issues selected and the implications for practitioners and researchers are explored.
\end{abstract}

Keywords: Information technology return, Project management, Information systems, Information technology success variables, technology solutions, productivity paradox

\section{INTRODUCTION}

There has been considerable debate on returns on information technology (IT) investment. The concept of a productivity paradox in IT has been suggested for decades. The idea is that monies are being spent on information technology but no corresponding increase in overall company productivity has been experienced. Some researchers have supported these concepts, others disagree. Almost all researchers have used corporate or government data in an attempt to determine relationships between investment and returns. An alternative approach is to inquire within an organization itself to see how information technology is viewed within companies. This study reviews the responses to a broad based questionnaire sponsored by the Financial Executives International Organization and Computer Sciences Corporation and specifically asks top financial executives how much return they are receiving on their information technology investments. This presents a direct approach to determining IT productivity.

In addition, there has been discussion on how well information technology return has progressed over recent years. A major HBR article [5] suggested that IT doesn't matter anymore. Has IT declined as a provider of return either through cost savings or revenue enhancement? This study reviews data from 2003 as well as 2006 to see if significant change took place.

Finally, this study explores detail behind the gross numbers to better understand information technology today. Specifically, both 2003 and 2006 data are analyzed to determine what the critical issues are in IT. These areas are reviewed to determine change over time as well.

As a result, a comprehensive inside look at information technology within top organizations today is presented. The last major peer-reviewed explorations of information technology issues was in 1999 [9] and 1996 [3]. We have sought to determine current levels of return as well as change over time. In addition, what the up-to-date key issues are for IT and how they are evolving are explored.

\section{INTRA-FIRM STUDIES AND IT ISSUES}

As noted, there have been very few studies that have looked within a firm. Most studies within a firm examined a specific application such as the Pennsylvania turnpike commission. There are a few articles that examine organizational perception of overall information technology returns. With one of the few, Brynjolfsson and Hitt [4] correlated the Informationweek 500 annual survey and analyzed results from 175 chief information officers.

There are also few studies that examine the top information technology issues that organizations face today. Understanding the current important information technology issues is essential to 
improving organizational performance and preparing proper curriculum to educate new IT students.

It has been nearly 15 years since an MISQ article addressed key information issues [3]. Table 1 provides what they considered the most important issues in 1996.

Table 1. Brancheau et al. Issues 1996 [3]

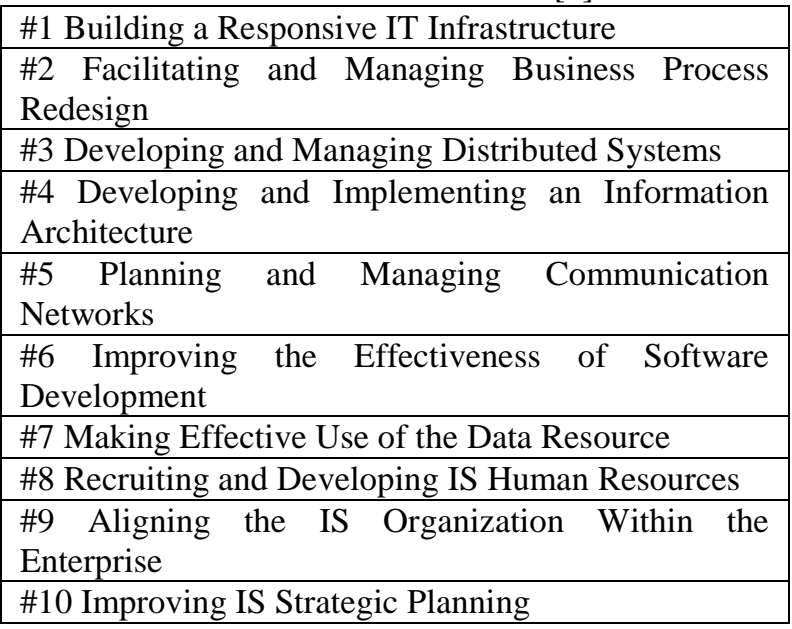

A follow-up study in 1999 [9] surveyed IS practitioners and found the top ten "IS Issues" shown in Table 2.

Table 2. Kim and Kim Issues 1999

Competitive advantage and strategic IS

Telecommunications and Networking

Disaster Recovery

Improving information security and control

Having a responsive IT infrastructure

Software reengineering and maintenance

Developing information architecture

Improving IS strategic planning

Client/server computing

IS Organizational Alignment

There are many issues shown that are included in both the Brancheau and Kim and Kim studies, including IS strategic planning, IT infrastructure, and IT organizational alignment.

One group who has been active recently in trying to determine top information technology issues is the AICPA [1]. They have conducted this survey for several years. The following are the 2006 Top 10 Technologies (and five additional). Those new to the list are noted.

Table 3. AICPA IT Issues 2006 [1]

1. Information Security.

\begin{tabular}{|c|}
\hline $\begin{array}{l}\text { 2. NEW Assurance and Compliance Applications } \\
\text { (e.g. SOX 404, ERM). }\end{array}$ \\
\hline 3. $\quad$ Disaster and Business Continuity Planning. \\
\hline NEW IT Governance. \\
\hline 5. NEW Privacy Management. \\
\hline $\begin{array}{l}6 . \quad \text { Digital Identity and Authentication } \\
\text { Technologies. }\end{array}$ \\
\hline $\begin{array}{ll}\text { 7. } & \text { Wireless Technologies. }\end{array}$ \\
\hline 8. Application and Data Integration. \\
\hline 9. $\quad$ Paperless Digital Technologies. \\
\hline 10. NEW Spyware Detection and Removal. \\
\hline $\begin{array}{l}\text { 11. E-mail Filtering including Spam and Malware } \\
\text { scanning. }\end{array}$ \\
\hline 12. Outsourcing. \\
\hline 13. Storage \& Backup Technologies. \\
\hline 14. Patch \& Network Management Tools. \\
\hline
\end{tabular}

A peer-reviewed literature review of top information technology issues yields very little results. Survey studies within IT firms sometimes take the form of examining the reasons for IT success or failure as Whittaker [12]. Rigby and Bilodeau [11] examined 25 most popular management tools including strategic planning, CRM, and SCM. But these are not directly the most important IT issues.

Perhaps one of the closest studies was prepared by Wilcoxson and Chatham [13]. The authors collected data from IT managers and business counterparts. Though their study focused on the IT/business relationship, there are relevant findings. They found that IT's alignment with business strategy was significantly increased over their 3 year period (19982000).

\section{HYPOTHESES}

As a result of the literature review, the following hypotheses were developed.

Many studies on the productivity paradox have suggested good returns on information technology investment [6], [10], [2]. In addition, Wilconsson and Chatham [13] suggested improvement over recent time in information technology alignment. As a result hypothesis one is proposed.

Hypothesis one:

Information technology will show at least moderate return on investment according to top financial executives.

Some authors such as Carr [5] have suggested that IT is not that important anymore. He views it as more of 
a commodity or method of doing business. Thus, it is suggested that if there are gains that they will not either improve or decline.

Hypothesis two:

Levels of information technology returns did not significantly change from 2003 to 2006

Early studies of information technology issues have shown many of the same key issues [3], [9], [1]. It is therefore proposed that there will be little change in issues from 2003 to 2006.

Hypothesis three:

There was little or no change in key technology issues facing organizations from 2003 to 2006.

\section{METHODOLOGY}

In order to test these hypotheses, specific data were required from actual corporations. We found a rich and robust dataset that was available from Financial Executives International. Financial Executives International is "the preeminent association for CFOs and other senior finance executives." It has ... CFOs, VPs of Finance, Treasurers, Controllers, Tax Executives, Academics, Audit Committee members [in] companies large and small, public and private, cross-industry [8]. In 2003 the FEI commissioned a large scale study of "technology issues for Financial Executives". The survey instructions follow.

"Financial Executives International (FEI) and Computer Sciences Corporation (CSC) are conducting the sixth annual survey of Technology Issues for Financial Executives. This initiative explores and reports on information technology from the perspective of the financial executive. Through this survey, we will gain current perspectives on topics such as: the most important financial management issues; the role of technology in enabling (or constraining) decision making and business operations; the impact of technology on business strategy; and the methods used to evaluate technology investments, among others.

$\cdots$

I. Demographics

II. Top Financial Management Issues

III. Information Systems Strategies

IV. Technology Applications

V. Managing the IS Function

." [7]

As a part of this study, specific information was obtained from top financial executives on IS success, and top information technology issues. This study had been conducted for the last several years including the data available years 2003 and 2006 . The questions and responses were sufficiently detailed and pertinent to our hypotheses to serve as the bases for testing this study's hypotheses. The main advantages are the large data set and the independent collection from a private membership trade group. The years 2003 and 2006 were selected due to availability of the data as well as a significant enough time gap.

All data has been collected and furnished by the Financial Executives International and Computer Sciences Corporation and remains their property. Use for academic and research purposes was obtained by the author. The author wishes to sincerely thank the organization for their cooperation.

All questions were analyzed using SPSS 15.0 and a variety of statistical techniques. The survey was conducted in 2003 and 2006 and overall results were included and compared accordingly. There were generally 459 usable responses for 2003 and 526 for 2006 or a total of 985 .

\section{RESULTS}

The first relevant question in the survey relates to top financial executives' view of return. "What overall return is your organization obtaining on its technology investments? (Mark only one.)

High, Medium, Low, Negative, Unknown”

This question is abbreviated as "return" in the tables four and five.

Hypothesis one:

Information technology will show at least moderate return on investment according to top financial executives.

Table 4. Return Statistics

\begin{tabular}{|l|l|l|l|l|}
\hline & & & $\begin{array}{l}\text { Std. } \\
\text { Std. } \\
\text { Deviation }\end{array}$ & $\begin{array}{l}\text { Error } \\
\text { Mean }\end{array}$ \\
\hline Return & 985 & 2.1411 & .68475 & .02182 \\
\hline
\end{tabular}

To test the hypothesis one, an overall mean for both years was calculated. As seen in table 4 that mean was 2.14 on a one to four scale where one was high, two was medium, three was low, and four was negative. The 2.14 mean suggested that returns were slightly worse than medium and a one sample test showed that returns were significantly different from an overall medium test value of 2.0 at $\mathrm{p}<.001$. Therefore hypothesis one was rejected (reject the null hypothesis that there is no significant difference). 
Information technology returns are seen as a significantly unfavorable versus medium by financial executives. Neither 2003 nor 2006 showed at least medium returns. Table 5 shows that both 2003 and 2006 returns were worse than 2.0. They were both significantly worse at $\mathrm{p}<.001$.

Table 5. Group Statistics 2003 and 2006

\begin{tabular}{|c|c|c|c|c|c|}
\hline & indicator & $\mathrm{N}$ & Mean & $\begin{array}{l}\text { Std. } \\
\text { Dev. }\end{array}$ & $\begin{array}{l}\text { Std. } \\
\text { Error } \\
\text { Mean }\end{array}$ \\
\hline \multirow[t]{2}{*}{ Return } & 2003.00 & 459 & 2.1852 & .69190 & .0323 \\
\hline & 2006.00 & 526 & 2.1027 & .67677 & .0295 \\
\hline
\end{tabular}

Hypothesis two:

Levels of information technology returns did not significantly change from 2003 to 2006.

Though both 2003 and 2006 were significantly below medium in returns, there was some improvement seen between 2003 and 2006. Testing this difference for significance results in finding that the difference is significant at $\mathrm{p}<.059$. This level of significance is modest but $\mathrm{p}<.10$ is often used for social science research. Hypothesis two was rejected (reject the null hypothesis that there is no significant difference). Levels of information technology return significantly improved between 2003 and 2006.

The next area included in the survey explores key technology issues. They are provided with a list of issues (table 6) and they rank the issue as very critical, somewhat critical, or not a concern. Only very critical issues were included in this analysis so that KEY issues could be studied. The abbreviations shown in later tables for these issues are also shown in table 6.

Table 6. FEI Issues

\begin{tabular}{|l|l|}
\hline $\begin{array}{l}\text { Identifying the appropriate level of } \\
\text { technology investment }\end{array}$ & level \\
\hline Upgrading or replacing legacy systems & uplegacy \\
\hline $\begin{array}{l}\text { Evaluating or measuring the return on } \\
\text { technology investments }\end{array}$ & measRet \\
\hline Prioritizing technology investments & prioritize \\
\hline $\begin{array}{l}\text { Educating senior management on the } \\
\text { value of technology }\end{array}$ & edSenMgmt \\
\hline $\begin{array}{l}\text { Establishing and maintaining effective } \\
\text { dialogue between IT and users }\end{array}$ & dialogue \\
\hline $\begin{array}{l}\text { Identifying the appropriate level of } \\
\text { security for information and electronic } \\
\text { applications }\end{array}$ & security \\
\hline $\begin{array}{l}\text { Identifying how IT can improve or } \\
\text { influence business processes }\end{array}$ & improvProc \\
\hline $\begin{array}{l}\text { Using technology to drive business } \\
\text { change }\end{array}$ & drvBusChg \\
\hline $\begin{array}{l}\text { Training staff in new technologies and } \\
\text { upgrades }\end{array}$ & training \\
\hline $\begin{array}{l}\text { Developing disaster } \\
\text { capabilities }\end{array}$ & disRec \\
\hline Introducing wireless technologies & wireless \\
\hline Evaluating the adoption/use of XBRL & xbrl \\
\hline $\begin{array}{l}\text { Using technology to improve the } \\
\text { system of internal controls }\end{array}$ & intCntrl \\
\hline Aligning business and IT strategy & align \\
\hline
\end{tabular}

Hypothesis three: 
There was little or no change in key technology issues facing organizations from 2003 to 2006.

Table 7. FEI Issues Analysis

\begin{tabular}{|c|c|c|c|c|c|c|c|}
\hline & indicator & $\mathrm{N}$ & Mean & $\begin{array}{l}\text { Std. } \\
\text { Deviation }\end{array}$ & $\begin{array}{l}\text { Std. } \\
\text { Error } \\
\text { Mean }\end{array}$ & $\begin{array}{l}\text { Level of } \\
\text { Import. }\end{array}$ & Sig. \\
\hline \multirow[t]{2}{*}{ Level } & 2003 & 459 & 0.573 & 0.49518 & 0.02311 & Down & 0.000 \\
\hline & 2006 & 526 & 0.4411 & 0.49699 & 0.02167 & & 0.000 \\
\hline \multirow[t]{2}{*}{ Uplegacy } & 2003 & 459 & 0.3246 & 0.46874 & 0.02188 & UP & 0.740 \\
\hline & 2006 & 526 & 0.3346 & 0.4723 & 0.02059 & & 0.740 \\
\hline \multirow[t]{2}{*}{ measRet } & 2003 & 459 & 0.3159 & 0.46538 & 0.02172 & Down & 0.000 \\
\hline & 2006 & 526 & 0.1863 & 0.38973 & 0.01699 & & 0.000 \\
\hline \multirow[t]{2}{*}{ Prioritize } & 2003 & 459 & 0.5991 & 0.49061 & 0.0229 & Down & 0.000 \\
\hline & 2006 & 526 & 0.4639 & 0.49917 & 0.02176 & & 0.000 \\
\hline \multirow[t]{2}{*}{ edSenMgmt } & 2003 & 459 & 0.2919 & 0.45515 & 0.02124 & Down & 0.001 \\
\hline & 2006 & 526 & 0.1977 & 0.39866 & 0.01738 & & 0.001 \\
\hline \multirow[t]{2}{*}{ Dialogue } & 2003 & 459 & 0.4924 & 0.50049 & 0.02336 & Down & 0.005 \\
\hline & 2006 & 526 & 0.403 & 0.49098 & 0.02141 & & 0.005 \\
\hline \multirow[t]{2}{*}{ Security } & 2003 & 459 & 0.5621 & 0.49667 & 0.02318 & Down & 0.015 \\
\hline & 2006 & 526 & 0.4848 & 0.50024 & 0.02181 & & 0.015 \\
\hline \multirow[t]{2}{*}{ improvProc } & 2003 & 459 & 0.5163 & 0.50028 & 0.02335 & Down & 0.001 \\
\hline & 2006 & 526 & 0.4144 & 0.4931 & 0.0215 & & 0.001 \\
\hline \multirow[t]{2}{*}{ drvBusChg } & 2003 & 459 & 0.3878 & 0.48778 & 0.02277 & Down & 0.390 \\
\hline & 2006 & 526 & 0.3612 & 0.48081 & 0.02096 & & 0.391 \\
\hline \multirow[t]{2}{*}{ Training } & 2003 & 459 & 0.3094 & 0.46274 & 0.0216 & Down & 0.000 \\
\hline & 2006 & 526 & 0.1901 & 0.39276 & 0.01713 & & 0.000 \\
\hline \multirow[t]{2}{*}{ disRec } & 2003 & 459 & 0.3464 & 0.47634 & 0.02223 & Down & 0.033 \\
\hline & 2006 & 526 & 0.2833 & 0.45102 & 0.01967 & & 0.034 \\
\hline \multirow[t]{2}{*}{ Wireless } & 2003 & 459 & 0.0719 & 0.2586 & 0.01207 & UP & 0.720 \\
\hline & 2006 & 526 & 0.0779 & 0.26834 & 0.0117 & & 0.719 \\
\hline \multirow[t]{2}{*}{ Xbrl } & 2003 & 459 & 0.0196 & 0.1388 & 0.00648 & UP & 0.282 \\
\hline & 2006 & 526 & 0.0304 & 0.1719 & 0.0075 & & 0.275 \\
\hline \multirow[t]{2}{*}{ intCntrl } & 2003 & 459 & 0.268 & 0.44339 & 0.0207 & Down & 0.192 \\
\hline & 2006 & 526 & 0.2319 & 0.42247 & 0.01842 & & 0.194 \\
\hline \multirow[t]{2}{*}{ Align } & 2003 & 459 & 0.5251 & 0.49992 & 0.02333 & Down & 0.020 \\
\hline & 2006 & 526 & 0.4506 & 0.49802 & 0.02171 & & 0.020 \\
\hline
\end{tabular}

Table 8. FEI Issues Ranked

\begin{tabular}{|l|l|l|}
\hline & 2003 & 2006 \\
\hline
\end{tabular}




\begin{tabular}{|l|l|l|}
\hline Security & 0.5621 & 0.4848 \\
\hline Prioritize & 0.5991 & 0.4639 \\
\hline Align & 0.5251 & 0.4506 \\
\hline Level & 0.573 & 0.4411 \\
\hline improvProc & 0.5163 & 0.4144 \\
\hline Dialogue & 0.4924 & 0.403 \\
\hline drvBusChg & & \\
& 0.3878 & 0.3612 \\
\hline Uplegacy & 0.3246 & 0.3346 \\
\hline disRec & 0.3464 & 0.2833 \\
\hline intCntrl & 0.268 & 0.2319 \\
\hline edSenMgmt & & \\
& 0.2919 & 0.1977 \\
\hline Training & 0.3094 & 0.1901 \\
\hline measRet & 0.3159 & 0.1863 \\
\hline Wireless & 0.0719 & 0.0779 \\
\hline Xbrl & 0.0196 & 0.0304 \\
\hline
\end{tabular}

The top issues facing organizations in 2006 were in order of priority security, prioritizing technology investments, and aligning business and information technology strategy (table 8). The same issues were near the top of the latest in 2003 as well. In 2003, identifying the appropriate level of technology investment was higher in priority than in 2006. This suggests that information technology spending may be under better control in 2006. As noted, nearly all items showed an overall decrease in the level of importance and criticality between 2003 and 2006. Of the fifteen issues there were significant decreases in criticality in twelve (table 7). Hypothesis three was rejected. There was significant change in key technology issues facing the organizations between 2003 and 2006. Twelve of the fifteen issues showed significant decline in importance. Though some items may have changed significance in more recent years, the analysis presents areas that require examination.

\section{CONCLUSION AND IMPLICATIONS}

This manuscript studied the views of top financial executives over the three year period 2003 to 2006. A large sample of major executives shared their views on the returns currently generated from information systems in their organization. In addition, they rated the key technology issues facing their companies. Overall a group of about 500 executives participated in the survey. The sample and findings are therefore fairly robust. Generally, Information Systems (IS) are seen as providing below medium returns both in 2003 and 2006. But statistically it has been determined that there has been an improvement in returns on information technology investment. There was little change in issues seen as critical or not between 2003 and 2006. Overall, there were many issues that showed significant decline as "very critical" technology issues, Critical issues that were significantly less important in 2006 compared to 2003 included identifying the appropriate level of technology investment, evaluating or measuring the return on technology investment, educating senior management, establishing and maintaining effective dialogue between IT and users, identifying the appropriate level of security, identifying how IT affects business process, training staff, developing disaster recovery, and aligning business and IT strategy. This study has interesting implications for practitioners and researchers.

Practitioners can benchmark the consensus view of top financial executives on how well their information technology returns measure up to others. Those who are below norm should consider methods of addressing the shortfall. Those who believe they are above norm should carefully review how they achieved these results and take steps to continue and improve these practices. Specific issues which have been shown to be important can be used as a guide to prioritizing projects within individual organizations. Though there may be some variation across industries and company size, the list of issues should be able to be used to improve IT performance. It is interesting to note the decline in criticality of importance in many issues between 2003 and 2006. This suggests that many issues are being addressed more appropriately and the IT is performing better, though returns are still below medium.

Researchers can expand on these preliminary findings and develop new surveys and research approaches that review IT productivity from the inside out. Though these results only view top financial executives perceptions, they can be used as a starting point for detailed exploration into organizational IT performance as well as areas for attention and improvement. A limitation of the study is that the results only reflect the views of only top financial executives. There is opportunity to replicate the study with other groups to confirm findings. As an example, CEOs may have different criteria than CFOs.

Overall, this study has presented an up-to-date review of current insider views on information technology return, issues, and areas for improvement. The study updates the MISQ 1996 and IRMJ 1999 review and provides a fresh perspective on the performance of IT and its issues. In general, performance is seen as slightly below medium and improving. There appears 
to be room for further improvement. Particular attention should be paid to security, IT prioritization, and IT alignment as suggested in the survey results (table 8).

\section{REFERENCES}

1. AICPA (2006) Top Technologies http://infotech.aicpa.org/Resources/Top+Tec hnology+Initiatives/Top+10+Technologies+ $\underline{\text { Archive/2006/ }}$

2. Bharadwaj, A., Bharadwaj, S., and Knosynski, B. (1999). Information technology effects on firm performance as measured by Tobin's q. Management Science, 45(6), 1008-1024.

3. Brancheau, J., Janz, B., and Wetherbe, J. (1996). Key issues in information systems management: 1994-95 SIM Delphi results. MIS Quarterly. 20(2), 225-242.

4. Brynjolfsson, E. and Hitt, L. (1997, September 22 ). Breaking Boundaries. Informationweek, 54-61.

5. Carr, N. (2003), "IT Doesn't Matter", Harvard Business Review. 81(5), 5-12.

6. Dewan, S. and Kraemer, K. (1998, August). International dimensions of the productivity paradox. Communications of the ACM, 41,8 $56-62$.

7. FEI (2003), 2003 FEI/CSC Study Technology Issues for Financial Executives, Financial Executives International.

8. FEI (2006), About FEI, Available http://www.fei.org/about/us.cfm

9. Kim, Y. and Kim, Y. (1999). Critical IS issues in the network era. Information Resources Management Journal, 12(4), 1423

10. Lehr, B., and Lichtenberg, F. (1999, April). Information technology and its impact on productivity: Firm-level evidence from government and private data sources, 19771993. The Canadian Journal of Economics. 32(2), 335-362.
11. Rigby, D. and Bilodeau, B. (2005). The Bain 2005 management tool survey Strategy \& Leadership, 33(4), 4+

12. Whittaker, B. (1999). What went wrong? Unsuccessful information technology projects Information Management \& Computer Security. 7(1), 23+

13. Willcoxson, L. and Chatham, R. (2004). Progress in the IT/business relationship: a longitudinal assessment. Journal of Information Technology. 19(1), 71+ 